dulness. The urine was clear, but was not examined for albumin. At 6 A.M. on Feb. 11th the following condition was noted. The patient had a restless night, with very little sleep, and complained of severe headache. The temperature was $100^{\circ}$ and the pulse-rate was 100 . He was not at all drowsy. The urine passed during the night had been inadvertently thrown away. At 9 A.M. the patient was sleeping heavily, with an inclination to stupor, but as he had had a veronal powder (seven and a half grains) the night before little notice was taken of this. The pulse was 120 and the respirations had become more rapid. At $10.30 \mathrm{~A}$.M. he was comatose; the pupils were moderately dilated, there being neither light nor conjunctival reflex; the respirations were laboured and over 50 per minute, and the pulse was 160 , dicrotic, and the impulse sharp. There were moist sounds all over the right lung, especially at the base anteriorly. The heart showed a regular heaving apex impulse, the temperature was $106^{\circ}$, and the surface of the body was warm and inclined to sweat. diagnosis of commencing pneumonia was made. The comatose condition was looked upon as being of uræmic origin, and vigorous treatment was commenced; onethirtieth of a grain of strychnine was injected subcutaneously and oxygen was administered continuously. An ice cap was applied to the head and the surface of the body was sponged with ice-cold cloths. The temperature fell to $104^{\circ}$ and remained at that level for some time, with a tendency to rise to $105^{\circ}$ when sponging was relaxed. At 11.30 the respiration suddenly and unaccountably failed, the face became deeply cyanosed, and for about 20 seconds the patient remained in this condition; the pulse continued to beat vigorously, and artificial respiration was resorted to, not with any definite hope of the patient resuming breathing but more as a matter of routine and, in view of the strong cardiac action maintained for a period of seconds. After a few seconds of vigorous handling the respiration was gradually resumed and restored to its former rhythm. The temperature remained high. The patient showed no signs of improvement, so at 12 midday the median basilic vein was opened; the bleeding was not satisfactory, about 10 ounces of dark venous blood being removed. The immediate effect of the bleeding, however, was satisfactory ; the patient's colour improved, his respirations became more regular and less rapia, but the coma continued. At 7 P.M. a pint and a half of blood-stained urine was removed from the bladder and when examined it was found to contain albumin in large quantity and fresh blood. The specific gravity of the urine was 1020; at this stage the respirations were about 48 and the pulse about 140. The patient continued in the same condition until about 8 P.M., when the symptoms deepened, and he gradually sank, dying at 9 o'clock on the same evening.

The case is instructive from several points of view. The rapid progress of the grave symptoms left but little time to do anything for the patient.

The question of diagnosis naturally was the most important point for immediate consideration. A patient, presumably well a few days before, is suddenly taken with an inflammatory attack, a rising temperature, rapid breathing with physical signs of pneumonia, and a rapidly advancing coma. Obviously, the pneumonia symptoms were not sufficient to account for the rapid collapse of the patient. The conditions that suggested themselves to our minds were uræmic coma, diabetic coma, or poisoning. The urine on the previous evening had been clear, no suspicion of blood being present. Uræmic poisoning as the cause of the coma was suggested (in addition to the blood in the urine) by the headache which had persisted for several days. The previous history of the patient, who suffered from some obscure eye troubles accompanied by headache without any obvious error of refraction, also gives support to the possibility of uræmic poisoning. It is a matter of regret that no post-mortem examination could be made in this case. The history of the case was quite unlike that of diabetic coma. The possibility of poisoning was suggested by the presence of a small bottle of chlorodyne, half emptied, in the bedroom; the condition of the pupils negatived poisoning by opium. The provisional diagnosis of pneumonia complicated by uræmic coma seems to be the most satisfactory.

The treatment resorted to undoubtedly prolonged the patient's life-oxygen relieved the cyanosis, ice reduced the temperature, and the effect of the unsatisfactory bleeding certainly supported the view that in similar and less severe cases this method of treatment is decidedly useful.
The most startling feature of the case was the sudden failure of respiration ; this, in the experience of both of us, was unique. We have seen as sudden failure in anæsthesia cases, but never during the course of an acute and rapid illness such as we had to deal with. The patient was to all appearances dead when artificial respiration was resorted to, and we shall not readily forget the sudden stoppage and the slow return of respiration under artificial respiratory movements.

Obviously in such severe cases there is small chance of doing much for the patient. The experience gained in this case strengthens our bands in the consideration of future, and let us hope less grave, conditions. In view of the very stinted bleeding from the median basilic vein it might be better to open the external jugular, and so directly relieve the over-gorged central circulation. Oxygen should be used freely, and subcutaneous injection of fresh saline solution might be useful in relieving the condition.

Highgate, $N$.

\section{A TROPICAL FORM OF ADENITIS APPARENTLY DUE TO AN AS YET UNRECOGNISED ORGANISM.}

By R. LEONARD LEY, M.B. CANTAB, M.R.C.S. ENG. L R.C.P. LOND.

I HAVE seen recently three cases of adenitis that would come under this heading, and as I believe little is known about the disease in this country, and find no reference to it in the standard medical works or text-books, I thought the cases worth recording. What little I have learnt is from the patients themselves and from the examination of the glands from the first case. My three cases have been in soldiers who had recently served in Burma and Northern India, where apparently it is common.

CASE 1.-The patient, who had been home from Burma for one year, attended the out-patient department of St. Mary's Hospital, London, at the end of August, 1907, and was admitted under the care of Mr. S. Maynard Smith early in September. He gave the following history. He had noticed swellings in the groins about 18 months previously. These had gradually grown larger, as the result, he thought, of playing football. He had on admission masses of enlarged glands in both groins, of the size of a large closed fist. Some of the glands were soft and the individual glands moved fairly freely on one another and on the surrounding tissues. The skin over the glands was thinned, and in one place on the right side undermined. He denied all venereal disease and there were no signs of syphilis. There were no enlarged glands in other parts. The history was too long for malignant disease, primary or secondary, and there was no evidence of primary disease. Clinically the glands had all the characteristics of tubercle, and in spite of the unusual situation, the good health of the patient, and the absence of any other tubereulous lesion that diagnosis, faute de mieux, was made. The glands were removed, and on cutting into them after removal they were found strongly to resemble tuberculous gland. Some of the glands were of the size of pigeons' eggs and were riddled with foci of caseous material which was of a greenish-yellow colour and was of softer consistency than that usually found in tuberculous glands. The colour, however, was the main point of difference, being very unlike the creamy-white appearance of a broken-down tuberculous gland. The glands were examined in the pathological laboratory of the hospital, and when examined microscopically the changes found were quite unlike those found in tuberculous adenitis; there were none of the characteristic tubercles with giant cells, and in spite of repeated attempts, no tubercle bacilli or any other organism could be stained. It seemed certain, however, from the microscopical findings that some organism, whose staining affinities were unknown, was present, which produced a chronic inflammation going on to necrosis in much the same way as the tubercle bacillus. It was then suggested that it might be some form of tropical disease, and on questioning the patient I discovered that such a disease existed which attacked men and aninuls (horses and mules), that the glands in the groin were those usually attacked, and that the animals got the disease from cracks in their hoofs from 
hot dry sandy soils, and the men were supposed to get it from the animals, or from sores on their feet. 'The wounds healed well, the patient leaving the hospital at the end of three weeks.

CASE 2.-The patient whose case I have just narrated told me when in attendance upon him that a man in the opposite bed in the same ward, who had been admitted for some nasal trouble, was an old soldier who, while serving in Burma, had apparently contracted this disease. He had been in hospital in Burma for three months with glands in both groins, which had formed abscesses and had discharged and healed alternately in spite of all treatment until they were removed. Afterwards the wounds healed perfectly and he had then sound scars in both groins. This man must, I think, have had the same disease as the patient in Case 1, as the unusual site in a healthy man excludes tuberculosis, and he denied any venereal complaint at the time; also the treatment of excision is unlikely to have been required.

CASE 3. - The third case is one which I saw in December, 1908 , at Great Yarmouth, the patient being a soldier who had come home from Northern India in March of that year. He had at that time slight swelling of the left leg, but he was positive that he had no swelling in the groin. Since then he had developed swellings in the groin and at the back of the knee, which had involved the skin and had discharged. He sent for me because the leg had become more swollen and he feared blood poisoning. He had then three sores on the outer side of the ankle over the external malleolus and front of the ankle-joint. The glands in the popliteal space and in the groin were enlarged, and the skin over them was ulcerated ; the ulcers had a dry base, were rather wash-leathery in appearance, and of the same greenish-yellow colour as the section of the glands in the first case. There was œdema of the lower part of the leg, which pitted on pressure. Otherwise the man was perfectly healthy and there was no history or any sign of syphilis. The places all healed in the course of a month or two under a régime of cleanliness and antisepsis. This patient, too, knew of the disease and its association with horses, and he thought that he had contracted it from sores obtained while in a cavalry regiment in India.

These cases seem to me to be examples of a disease which, although it is probably well known in the tropics, is little known in this country. Its characteristics seem to be : (1) that it may lie latent for a long time (months at any rate), and this being so, cases may appear to develop in this country; (2) that the glands attacked are those of the groin and popliteal space, indicating the probable route and mode of infection, namely, from sores on the feet and from an organism living in the soil ; and (3) that animals contract the disease and possibly infect human beings. The two most characteristic features are the situation of the glands attacked and the chronicity. I know of no disease that combines these two symptoms. Syphilis affects the glands in the groin in the primary stage, but then there is the primary sore, and in the secondary and tertiary stages there are other signs. Tubercle bears the closest resemblance, but it rarely, if ever, attacks the inguinal or femoral glands, especially in healthy subjects. Tumours should be easily distinguished by their more rapid rate of growth and by the presence of a primary growth if the glandular mass be secondary. Septic processes are much more acute. Hodgkin's disease affects many areas, and the feel of the glands is characteristic ; also they rarely break down.

These cases, with the statements made by the patients and the pathological report on the first case, go to prove the existence of a tropical disease with the above-mentioned features. I suggest as a possibility that the disease may bear the same relation to bubonic plague that cow-pox does to small-pox, and that it may in the same way as cow-pox be transmitted to man.

I am indebted to Mr. Maynard Smith for permission to make use of the notes of Case 1.

Great Yarmouth.

The Water-supply of Ilsington (Devon).At a meeting of householders, parishioners, and ratepayers of Ilsington held on May 21st, it was resolved to urge the Local Government Board to sanction immediately the proposed scheme for an adequate supply of pure water, or to induce the rural district council to provide an alternative scheme.

\section{AN INVESTIGATION OF THE ACTION OF DIGESTIVE FERMENTS AND TISSUE EXTRACTS, HYPODERMICALLY INJECTED, ON MALIGNANT TUMOURS IN MICE.}

\section{BY J. A. SHAW-MACKENZIE, M.D. LOND.}

I WAS the first to employ pancreatic preparations, administered by the mouth and hypodermically in the treatment of inoperable cancer, ${ }^{1}$ solutions of trypsin for hypodermic use originally having been prepared for me by Mr. F. W. Gamble. The trypsin treatment of carcinoma has now received extended trial. The method used has been chiefly that of hypodermic injection. Many observers, both in this country and abroad, have in the main confirmed the conclusion I arrived at some time ago-namely, that while necrotic changes may be induced by injections of trypsin in the neighbourhood of the growth this cannot be accepted as evidence of the successful treatment of cancer, while in some cases there appears to have been an advance of the disease rather than its retrocession. ${ }^{2}$

Without entering into the grounds that later led me to suggest a modified ferment treatment I drew attention to the possible advantages of employing a combination of ferments from pancreas, liver, and intestine ${ }^{3}$ and particularly to the ferment erepsin which Cohnheim first discovered in the intestinal mucous membrane, and which Vernon ${ }^{4}$ has found to be of widespread occurrence in other tissues and organs.

A ferment of the liver independently described by von Leyden and Bergell appears to be of the same nature as Vernon's tissue erepsins ; the action of these ferments is different from that of trypsin; the latter acts on the native proteins, cleaving them into simpler products, and is therefore termed proteolytic or proteoclastic; erepsin and von Leyden and Bergell's ferment acts only on proteoses and peptone, cleaving them into amino acids; they may, therefore, be termed peptolytic or peptoclastic.

The intracellular action of tissue erepsin (and of other intracellular enzymes) undoubtedly plays an important rôle in tissue metabolism and is probably a factor in the defensive processes of the body; I advanced the theory (subsequently adopted independently by von Leyden and Bergell in reference to their ferment) $)^{j}$ that this agent might be deficient in cases of carcinoma.

I shall not here enter into any details regarding the clinical use of erepsin alone or in combination with other enzymes, for this method of treatment has still only reached an experimental stage; I desire here only to draw attention to an investigation I have made as to the effect hypodermic injections of intestinal extract (erepsin) alone or in combina. tion with extracts of liver and pancreas have on inoculated malignant tumours in mice.

Having no laboratory accommodation of my own the executive committee of the Imperial Cancer Research Fund placed facilities and material at my disposal for this purpose. At the time that I suggested this investigation no therapeutical application of these additional extracts by hypodermic injection had been made. The extracts employed were mainly supplied by Messrs. Allen and Hanburys. Dr. Vernon, at my request, also very kindly sent me some preparations of liver, pancreatic and intestinal extract, and Professor S. G. Hedin (Upsala), at my request, very kindly furnished me with every information as regards the splenic extract used. In every case the injection was made subcutaneously away from the growth and not into it. The following extracts were employed.

1. (ilycerine extract of duodenal and intestinal mucosa (pig). The undiluted extract is very toxic, five minims being a lethal dose for a mouse. The dose which can be borne of the diluted extract varies in individual mice, but the average for a series found to be well borne is 15 minims of extract diluted threefold with physiological saline solution; this may be briefly expressed as 15 minims of a quarter dilution

1 Tire Laxcra, Jan. 14th (p. 120) and Feb. 11th (p. 386), 1905.

2 Brit. Med. Jour., July 7th, 1906 ; Medical Press and Circular, July 17 th, 1907

$$
\begin{aligned}
& \text { 3 Brit. Med, Jour., Yareh 24th, } 1906 . \\
& \text { 4 11. M. Vernon : Journal of Physiology, 1904-0 }
\end{aligned}
$$

